\title{
Progestin effects on cell proliferation pathways in the postmenopausal mammary gland
}

\author{
Charles E Wood ${ }^{1}$, Daniel Branstetter ${ }^{2}$, Allison P Jacob ${ }^{3}$, J Mark Cline ${ }^{1}$, Thomas C Register ${ }^{1}$, Kathy Rohrbach², \\ Li-Ya Huang ${ }^{2}$, Hermina Borgerink ${ }^{1}$ and William C Dougall ${ }^{3^{*}}$
}

\begin{abstract}
Introduction: Menopausal hormone therapies vary widely in their effects on breast cancer risk, and the mechanisms underlying these differences are unclear. The primary goals of this study were to characterize the mammary gland transcriptional profile of estrogen + progestin therapy in comparison with estrogen-alone or tibolone and investigate pathways of cell proliferation in a postmenopausal primate model.

Methods: Ovariectomized female cynomolgus macaque monkeys were randomized into the following groups: placebo (Con), oral conjugated equine estrogens (CEE), CEE with medroxyprogesterone acetate (MPA) (CEE + MPA), and tibolone given at a low or high dose (Lo or Hi Tib). All study treatment doses represented human clinical dose equivalents and were administered in the diet over a period of 2 years.

Results: Treatment with CEE + MPA had the greatest effect on global mRNA profiles and markers of mammary gland proliferation compared to CEE or tibolone treatment. Changes in the transcriptional patterns resulting from the addition of MPA to CEE were related to increased growth factors and decreased estrogen receptor (ER) signaling. Specific genes induced by CEE + MPA treatment included key members of prolactin receptor (PRLR)/signal transducer and activator of transcription 5 (STAT5), epidermal growth factor receptor (EGFR), and receptor activator of nuclear factor kappa B (RANK)/receptor activator of nuclear factor kappa B ligand (RANKL) pathways that were highly associated with breast tissue proliferation. In contrast, tibolone did not affect breast tissue proliferation but did elicit a mixed pattern of ER agonist activity.

Conclusion: Our findings indicate that estrogen + progestin therapy results in a distinct molecular profile compared to estrogen-alone or tibolone therapy, including upregulation of key growth factor targets associated with mammary carcinogenesis in mouse models. These changes may contribute to the promotional effects of estrogen + progestin therapy on breast cancer risk.
\end{abstract}

Keywords: Postmenopausal hormone therapy, Estrogen, Progestin, Tibolone, Breast cancer, Gene expression, RANKL, Denosumab

\section{Introduction}

Different types of postmenopausal hormone therapy (HT) have been widely used for more than 60 years to alleviate symptoms of menopause and prevent associated conditions such as osteoporosis. The primary form of HT during much of this time has been estrogen-alone therapy (ET) [1]. In the mid-1990s, the clinical use of estrogen plus progestin therapy (EPT) began after several studies demonstrated that progestins opposed the adverse

\footnotetext{
*Correspondence: dougallw@amgen.com

${ }^{3}$ Therapeutic Innovation Unit (TIU), Amgen Inc, Seattle, WA 98119, USA

Full list of author information is available at the end of the article
}

effects of ET on endometrial cancer risk [2]. These findings helped spur a rapid increase in EPT prescriptions from less than two million in 1995 to 24 million in 2001 [1]. At the time, the most common type of HT used in the US was conjugated equine estrogens (CEE) with or without the progestin medroxyprogesterone acetate (MPA), which together accounted for more than $60 \%$ of total HT prescriptions [1].

Use of HT fell dramatically in 2002 after the release of the primary results from the Women's Health Initiative (WHI) Estrogen + Progestin Trial [1,3]. In this large randomized clinical trial, postmenopausal women receiving

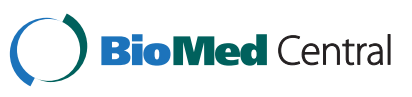


EPT (CEE + MPA) treatment had significantly higher incidence of invasive breast cancer compared with those taking the placebo $[3,4]$. Subsequent reports noted increased breast cancer mortality for women taking EPT [5] and decreased breast cancer incidence following discontinuation of EPT [6]. These results supported prior epidemiologic studies $[7,8]$ but differed from the sister WHI Estrogen-Alone Trial, in which CEE alone did not increase the incidence of invasive breast cancer among women with a prior hysterectomy $[9,10]$. Collectively, these studies confirmed that the promotional effects of EPT on certain types of breast cancer were greater than those seen with estrogen alone.

A prominent alternative to traditional menopausal HTs used outside the US is tibolone. This unique steroidal compound is converted in a tissue-selective manner to estrogenic, progestogenic, and androgenic metabolites. Estrogenic metabolites have been shown to reduce menopausal symptoms and fracture risk [11,12], whereas the progestogenic $\Delta-4$ isomer metabolite (selectively produced in the uterus) has been shown to provide endometrial protection from estrogenic effects $[13,14]$. However, the effects of tibolone therapy on breast cancer risk are controversial. In a randomized clinical trial of older postmenopausal women, tibolone therapy resulted in a significantly lower breast cancer risk [12], whereas in a separate clinical trial, breast cancer survivors had increased risk of recurrence following tibolone treatment [15].

Despite numerous preclinical and clinical studies, the mechanistic actions of different HTs on breast tissue have not been clearly defined. In mouse models, ovarian hormones contribute significantly to mammary gland carcinogenesis [16]; however, differences between mouse and human mammary gland anatomy, development, and/ or hormonal control of proliferation may limit the translational relevance of targets identified in the mouse for estrogen and progestogen function. Macaques are anthropoid primates with high overall genetic coding sequence identity to humans, including key genes related to breast cancer susceptibility [17]. Prior work has shown close similarities between macaque and human mammary gland biology, including responses to exogenous estrogen and progestogen therapies, sex steroid receptor expression, and age-related hyperplastic and neoplastic lesions [18]. This includes a study on aged rhesus macaques and suggests a lifetime incidence of mammary gland cancer at about 6\% [19], similar to lower-risk human populations. Previous studies in this model have also shown that the addition of a progestin to an estrogen increases mammary gland proliferation and density beyond that seen with estrogen alone, in support of the later WHI findings related to breast cancer risk [20]. The primary aim of this study was to assess the effects of long-term treatment with CEE, CEE + MPA, or tibolone on the transcriptional profiles and signaling pathways of the normal postmenopausal primate mammary gland. Our main goals were to identify specific targets associated with hormone-induced breast proliferation and evaluate their relations with candidate pathways known to drive mammary carcinogenesis in mouse tumor models.

\section{Methods}

\section{Study design and treatments}

This study utilized archived tissue samples from a parallelarm design experiment in which 149 ovariectomized adult female cynomolgus macaques (Macaca fascicularis) with a mean estimated age of six to eight years were randomized to receive one of the following five treatments for two years: placebo (control; $\mathrm{n}=31$ ); CEE at $0.042 \mathrm{mg} / \mathrm{kg}(\mathrm{CEE}$; $\mathrm{n}=28) ; \mathrm{CEE}+\mathrm{MPA}$ at $0.167 \mathrm{mg} / \mathrm{kg}(\mathrm{CEE}+\mathrm{MPA} ; \mathrm{n}=29)$; tibolone at $0.05 \mathrm{mg} / \mathrm{kg}$ (Lo Tib; $\mathrm{n}=30$ ); and tibolone at 0.2 $\mathrm{mg} / \mathrm{kg}$ (Hi Tib; $\mathrm{n}=31$ ). Dose equivalents approximated standard HT doses of CEE (0.625 mg/day) and MPA (2.5 $\mathrm{mg} /$ day) in postmenopausal women, and tibolone doses were designed to approximate $0.75 \mathrm{mg} /$ day (low) and 3.0 $\mathrm{mg} /$ day (high) doses in women. Serum concentrations of estrogens, MPA, and tibolone metabolites were similar to those reported in women taking comparable therapies [21]. Treatments were administered in the control diet with casein plus lactalbumin as the protein source and macronutrient composition based on a typical human diet in the USA [22]. Animals were housed in social groups of five animals each and fed $60 \mathrm{kcal} / \mathrm{kg}$ (plus $10 \%$ extra to account for waste) twice daily, with drug treatments split between the two feedings. Daily doses were scaled to $1,800 \mathrm{kcal}$ of diet (the estimated daily intake for a US woman) to account for differences in metabolic rates between monkeys and human subjects. All animals were considered multiparous based on historical data from the original breeding colony and uterine histology. Histology outcomes were described previously [21]; no mammary gland tumors were detected.

All procedures involving macaques in this study were conducted in compliance with State and Federal laws and standards of the US Department of Health and Human Services and were approved by the Wake Forest University Animal Care and Use Committee. The facilities and laboratory animal program of Wake Forest University are fully accredited by the Association for the Assessment and Accreditation of Laboratory Animal Care.

\section{Gene microarray analyses}

Mammary gland tissues were collected during necropsy at the end of the two-year treatment period [21], and designated portions were snap-frozen in liquid nitrogen and stored at $-70^{\circ} \mathrm{C}$ for gene expression analyses. Total mammary gland RNA was extracted from frozen samples using Tri Reagent (Molecular Research Center, Cincinnati, OH, USA), purified using RNeasy Mini kit (QIAGEN, Valencia, CA, USA), and quantitated using a NanoDrop ND-1000 UV-vis spectrophotometer (NanoDrop, Wilmington, DE, 
USA). Nucleic acid intactness and quality were confirmed using an Agilent 2100 Bioanalyzer (Agilent Technologies, Wilmington, DE, USA). Biotinylated cRNA samples were prepared according to the standard Enzo Bioarray ${ }^{\mathrm{TM}}$ protocol (Enzo Life Sciences, Farmingdale, NY, USA) and hybridized using the standard Affymetrix (Santa Clara, CA, USA) protocol for eukaryotic samples. Biotinylated cRNA from each sample was hybridized to Affymetrix GeneChip Rhesus Macaque Genome Arrays (Santa Clara, CA, USA), washed and stained in an Affymetrix GeneChip Fluidics Station (Santa Clara, CA, USA), and scanned with an Affymetrix GeneChip ${ }^{\circledR}$ Scanner 3000 (Santa Clara, CA, USA). Intensity data were extracted from scanned images and checked for quality using Affymetrix GeneChip Operating Software and Expression Console (MAS5 algorithm; Santa Clara, CA, USA). Microarray assays were performed at Beckman Coulter Genomics (Morrisville, NC, USA). Four randomly selected samples per group were run on microarray from control, CEE, CEE + MPA, and Hi Tib groups.

Microarray data analyses were performed using the GeneSifter $^{\circledR}$ software program (Perkin Elmer/Geospiza, Seattle, WA, USA). Intensity data were RMA-normalized, converted to a $\log _{2}$ scale, screened for heterogeneity among samples and groups, and evaluated using supervised analysis of variance (ANOVA) and pairwise comparisons between treatments. Principal components analysis (PCA), pattern navigation, cluster analysis, heat mapping, and KEGG pathway analyses were performed on filtered data subsets, as described in the Results section. Differences in gene numbers altered by each treatment were compared using either Fisher's exact test or chi-square test. Euclidean distances (representing the numeric difference between treatment vectors) were calculated as part of hierarchical clustering dendrograms using average linkage. Pathways related to cell proliferation were evaluated using $z$-scores generated in KEGG analyses; a $z$-score more than 2.0 was considered significant overrepresentation of genes in a particular pathway. All $P$ values were corrected when possible for multiple comparisons using the Benjamini and Hochberg method $\left(P_{a d j}\right)$, which derives a false discovery rate estimate from the raw $P$-values [23]. Representation of differentially expressed genes within specific functional categories was evaluated using Ingenuity Pathway Analysis software v6 (Ingenuity Systems, Redwood City, CA, USA) using a Fisher's exact test with Benjamini and Hochberg correction and expressed as $-\log _{10}$ of the $P$ value for gene numbers within each treatment group. Microarray data are publicly available on the NCBI Gene Expression Omnibus database (accession number GSE27228).

\section{Quantitative gene expression}

Expression of genes associated with proliferation, epithelial density, growth factor signaling, oestrogen receptor (ER) expression and activity, estrogen metabolism, and receptor activator of nuclear factor kappa-B (RANK)/RANK ligand (RANKL) pathway activity were measured in mammary gland samples using quantitative real-time reverse transcriptase polymerase chain reaction (qPCR). Macaquespecific qPCR primer-probe sets for internal control genes (glyceraldehyde-3-phosphate dehydrogenase (GAPDH); beta-actin $(A C T B)$ ) were generated through the Applied Biosystems Taqman Assay-by-Design service (Foster City, CA, USA). Sources for all target primer/probe sets are given in Additional file 1: Table S1. All probes spanned an exon-exon junction to eliminate genomic DNA amplification. qPCR reactions ( $20 \mu \mathrm{l}$ volume) were performed on an Applied Biosystems 7500 Fast Real-Time PCR system (Foster City, CA, USA) using standard Taqman reagents and thermocycling protocol [24]. Relative expression was determined using the $\Delta \Delta \mathrm{Ct}$ method. The $\mathrm{Ct}$ values for the control genes $G A P D H$ and $A C T B$ were averaged for use in internal calibration, and premenopausal breast tissue RNA was a reference for plate-to-plate parallel calibration. Calculations were performed using Applied Biosystems Relative Quantification 7500 Software v2.0.1 (Foster City, CA, USA).

\section{Immunohistochemistry}

Immunohistochemical (IHC) staining was performed on fixed paraffin-embedded mammary gland sections. Slides were deparaffinized, rehydrated in water, prepared by heat-induced epitope retrieval using Diva Decloaker (Biocare Medical, Concord, CA, USA) and Decloaking Chamber Plus (Biocare Medical, Concord, CA, USA) at heat and pressure cycles of $125^{\circ} \mathrm{C}$ for 30 and 10 seconds. Slides were gradually cooled by replacing the retrieval solution with deionized water and rinsed twice in wash buffer (Dako Wash Buffer, DakoCytomation Carpinteria, CA; five minutes) before loading on a Dako Autostainer (Dako North America Inc, Carpinteria, CA). Sections were blocked for endogenous peroxidases and nonspecific binding of staining reagents by sequentially incubating with $3 \%$ hydrogen peroxidase (hydrogen peroxidase block, Thermo Scientific Waltham, MA; 10 minutes), Avidin (Vector Labs, Burlingame, CA; 15 minutes), Biotin (Vector Labs, Burlingame, CA; 15 minutes), and TNB (Perkin Elmer; 20 minutes). Tris-NaCl-blocking buffer was removed and replaced with anti-human RANK (N-2B10.1 or N-1H8.1; Amgen, Seattle, WA) or RANKL (M366; Amgen, Seattle, WA) mouse monoclonal antibodies or isotype-matched control mouse IgG (BD Pharmingen, San Jose, CA) at concentrations of $5 \mu \mathrm{g} / \mathrm{mL}$ for anti-RANK and $1 \mu \mathrm{g} / \mathrm{mL}$ for anti-RANKL for 60 minutes. A biotinylated, goat antimouse IgG (Vector Labs, Burlingame, CA) secondary antibody in 10\% normal human serum Tris-NaCl-blocking buffer was applied at a concentration of $7.5 \mu \mathrm{g} / \mathrm{mL}$ followed by a 30 minute incubation. Slides were sequentially incubated 
with streptavidin-horseradish peroxidase (SA-HRP; Perkin Elmer, Waltham, MA; 30 minutes) at a 1:1500 dilution in TNB, tyramide signal amplification TSA (Perkin Elmer, Waltham, MA; five minutes) at a 1:100 dilution in amplification diluent (Perkin Elmer, Waltham, MA), and then SA-HRP (Perkin Elmer, Waltham, MA; 30 minutes) at a 1:1500 dilution in TNB. Slides were then incubated with diaminobenzidine chromogen (Dako, Carpinteria, CA; five minutes), counterstained with hematoxylin (Dako, Carpinteria, CA; 30 seconds), allowed to turn blue in tap water for two minutes before dehydrating with ascending concentrations of ethanol, cleared with xylene, and mounted.

The intensity of IHC staining was scored on a semiquantitative scale $(0=$ absent, 1 = weak, 2 = moderate, $3=$ intense), blinded to treatment group by a board-certified pathologist. Incidence was scored as a positive IHC signal (any intensity). Immunostaining of slides for Ki-67 antigen was described previously [21]. For dual labeling experiments, the following modifications to the above procedure were performed. Antigen retrieval was performed using Diva AR reagent (Biocare, Concord, CA; DV2004G1) at $90^{\circ} \mathrm{C}$ overnight in the Decloaking Chamber. Sections were blocked as described above, incubated with either antiprogesterone receptor PGR (Dako, Carpinteria, CA; M3569 at 1:40; 40 minutes) or anti-Ki-67 (Epitomics, Burlingame, CA; 4203-1 at 1:400; 60 minutes), detected with Dako Mouse or Rabbit Envision + Systems (Dako, Carpinteria, CA, 30 minutes), and visualized by Dako DAB+ (Dako, Carpinteria, CA, 10 minutes). Antibody staining from the first PR/Ki-67 IHC incubation/staining were blocked by rinsing sections in distilled water, eluting, and incubating the slides in Diva AR reagent (Biocare, Concord, CA) at $98^{\circ} \mathrm{C}$ for 10 minutes. Slides were washed and blocked as described above; followed by incubation with either antiRANKL (M366 at $2 \mu \mathrm{g} / \mathrm{mL}$ ), anti-RANK (N-1H8.1 at 5 $\mu \mathrm{g} / \mathrm{mL})$, or mouse IgG1 isotype control $(5 \mu \mathrm{g} / \mathrm{mL})$ for 60 minutes. Secondary antibody incubation was performed as described above, followed by incubation in streptavidin alkaline phosphatase, tyramide amplification and repeat of strepavidin alkaline phosphatase. Slides were then incubated with permanent red chromogen (Dako, Carpinteria, CA; 20 minutes), counterstained with Mayer's hematoxylin, washed and aqueous mounted. Histologic images were photographed using a Nikon Eclipse E600 microscope with a Nikon (Tokyo, Japan) DXM1200 digital camera. The resulting images were white-balanced using Adobe Photoshop CS software (San Jose, CA); no additional image modifications were employed.

\section{Statistical analyses}

Data were analyzed using the SAS statistical package v9 (SAS Institute, Cary, NC, USA). All data were evaluated for normal distribution and homogeneity of variances among groups. Gene expression data were evaluated using a nonparametric Kruskal-Wallis test followed by two-sided Wilcoxon rank sum pairwise analysis and reported as a fold-change of control with $90 \%$ confidence interval. One control group animal died during the course of the study, reducing the number of control animals to 30. All pairwise $P$ values were adjusted for the number of pairwise tests using a Bonferroni correction. Pre-planned pairwise tests included each treatment group versus control and CEE + MPA versus CEE and Hi Tib groups. Intensity of RANK/RANKL immunostaining was evaluated using a one-way ANOVA with Bonferroni's post test. To evaluate the correlation of gene or protein expression with IHC, data were log transformed and linear regression analysis was performed. A two-tailed significance level of 0.05 was used for all comparisons.

\section{Results}

\section{EPT elicits distinct effects on global gene expression profiles}

Global mammary gland expression profiles were evaluated by microarray analysis. A total of 52,865 array probe sets were detected at a quality score of more than 2.0. Of these, probes for 1,534 different genes were significantly altered at a fold change (FC) more than 1.5 and an adjusted ANOVA $P<0.05$. HTs resulted in distinct effects on mammary gland gene expression. Overall transcriptional effects were greatest for CEE + MPA and lowest for Hi Tib. For example, CEE + MPA resulted in a greater number of significantly altered genes versus controls $(\mathrm{n}=1405)$ compared with CEE $(\mathrm{n}=437)$ and Hi Tib $(\mathrm{n}=6)(P<0.0001)$ (Figure 1a). Among these genes, PCA and heatmap analysis showed modest overlap in transcriptional profiles for CEE and CEE + MPA and a profile for Hi Tib most similar to the control group (Figure 1b, 1c). Functional analysis of significantly altered genes showed overrepresentation of several categories related to cell proliferation and cancer risk (Figure 1d). The most highly represented functional gene category was cancer. Within this class, a greater number of differentially regulated genes was seen for CEE + MPA $\left(\mathrm{n}=497, P<10^{-34}\right)$ compared with $\operatorname{CEE}\left(\mathrm{n}=166, P=10^{-14}\right)$ and Hi Tib $(\mathrm{n}=2, P=0.01)$. Other functional categories showing greater overrepresentation in the CEE + MPA group included cellular movement, signaling, and interaction (Figure 1d).

\section{EPT increases cell proliferation and growth factor signaling markers}

Similar to global profiles, quantitative expression of specific markers for epithelial proliferation (antigen identified by monoclonal antibody Ki-67 (MKI67)) and density (keratin 19 (KRT19)) was highest for CEE + MPA, intermediate for CEE, and lowest for tibolone groups compared with placebo (Figure 2a). Treatment effects related to cell proliferation included the Jak/Stat and ErbB pathways, which 


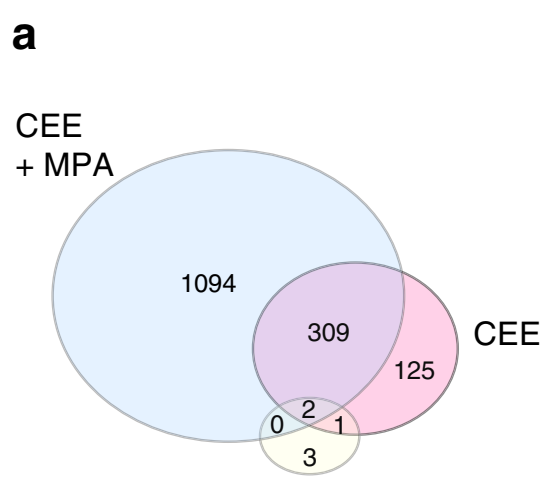

Hi Tib b

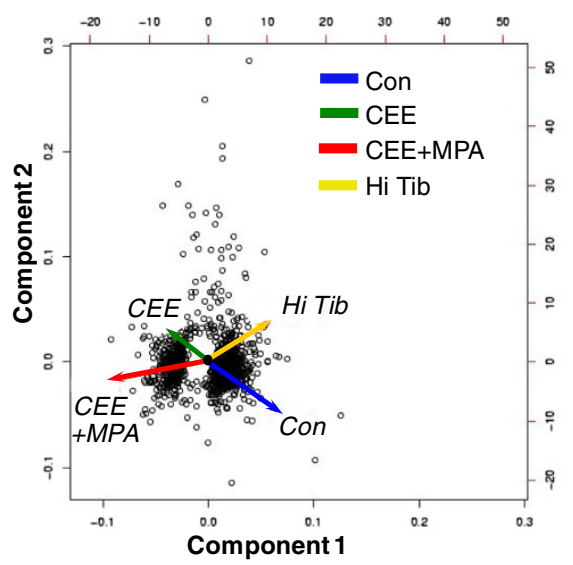

C
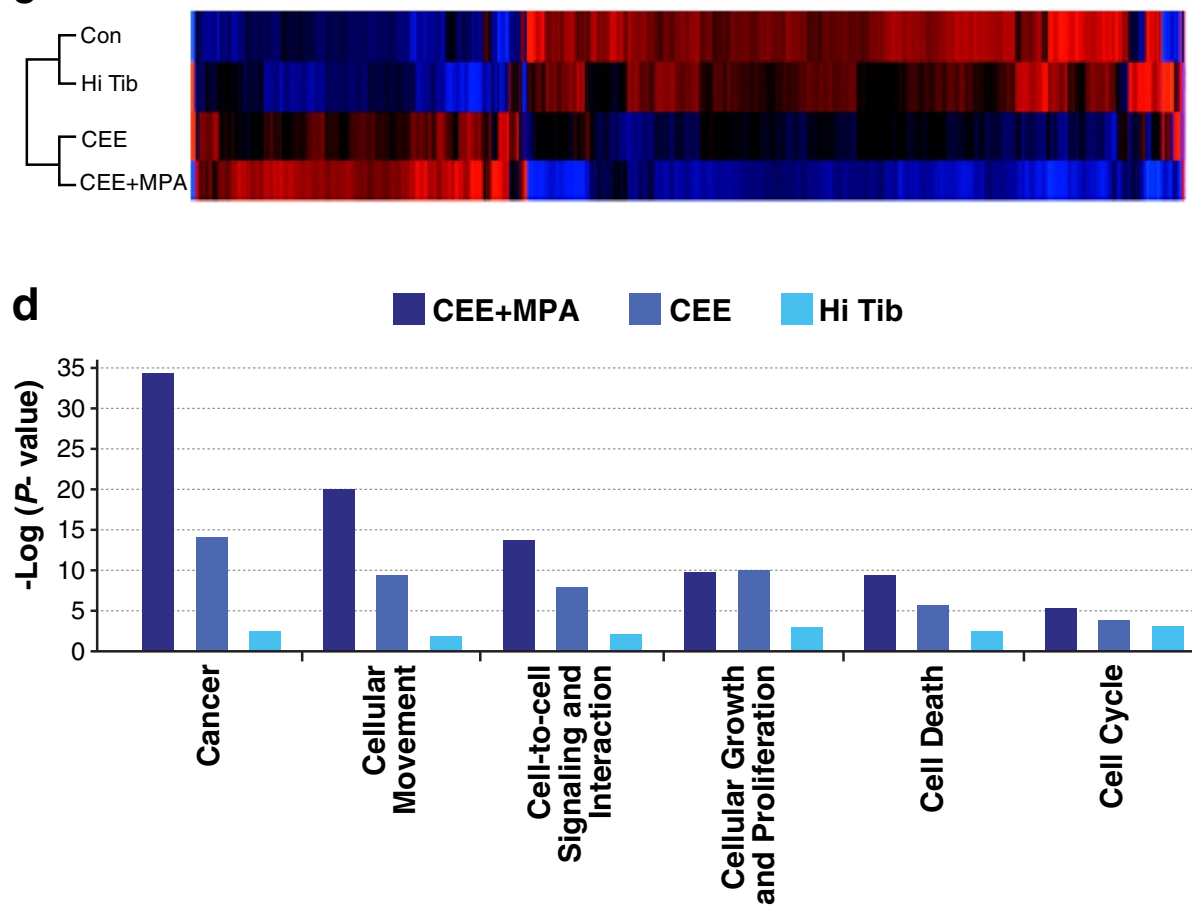

Figure $1 \mathrm{Global}$ transcriptional patterns in the breast tissue following treatment with control (placebo), conjugated equine estrogens (CEE), CEE + medroxyprogesterone acetate (MPA), and high-dose tibolone (Hi Tib). (a) Venn diagram showing greater numbers of genes altered by CEE + MPA compared with CEE and Hi Tib. (b) principal component analysis and (c) heatmap of differentially regulated genes showing greater overlap between Con and Hi Tib groups and the CEE + MPA and CEE groups. (d) Functional categories of significantly altered transcripts showing overrepresentation of genes involved in cancer and several related classes. mRNA profiles were determined by microarray analysis. All diagrams correspond to significantly altered transcripts with fold-change of more than 1.5 versus control group in at least one group, adjusted analysis of variance (ANOVA) $P<0.05$, and quality more than 2 .

were overrepresented among upregulated genes, and the transforming growth factor (TGF)-beta pathway, which was significantly overrepresented among downregulated genes. On microarray analysis, Jak/Stat and ErbB-related genes related primarily to signal transducer and activator of transcription 5 (STAT5) and epidermal growth factor receptor (EGFR) signaling pathways, respectively. On qPCR, expression of key molecules within these pathways was highest for CEE + MPA treatment, showing similar overall expression patterns to that seen for $M K I 67$ (Figure 2b, 2c) and high correlation for individual markers, particularly STAT5A and amphiregulin (AREG) $\left(R>0.7, P<10^{-20}\right.$ for both) [see Additional file 2: Figures S1a, S1b]. In contrast, no significant treatment effects were seen on qPCR for individual markers of TGF-beta pathway activity (Figure 2d). 

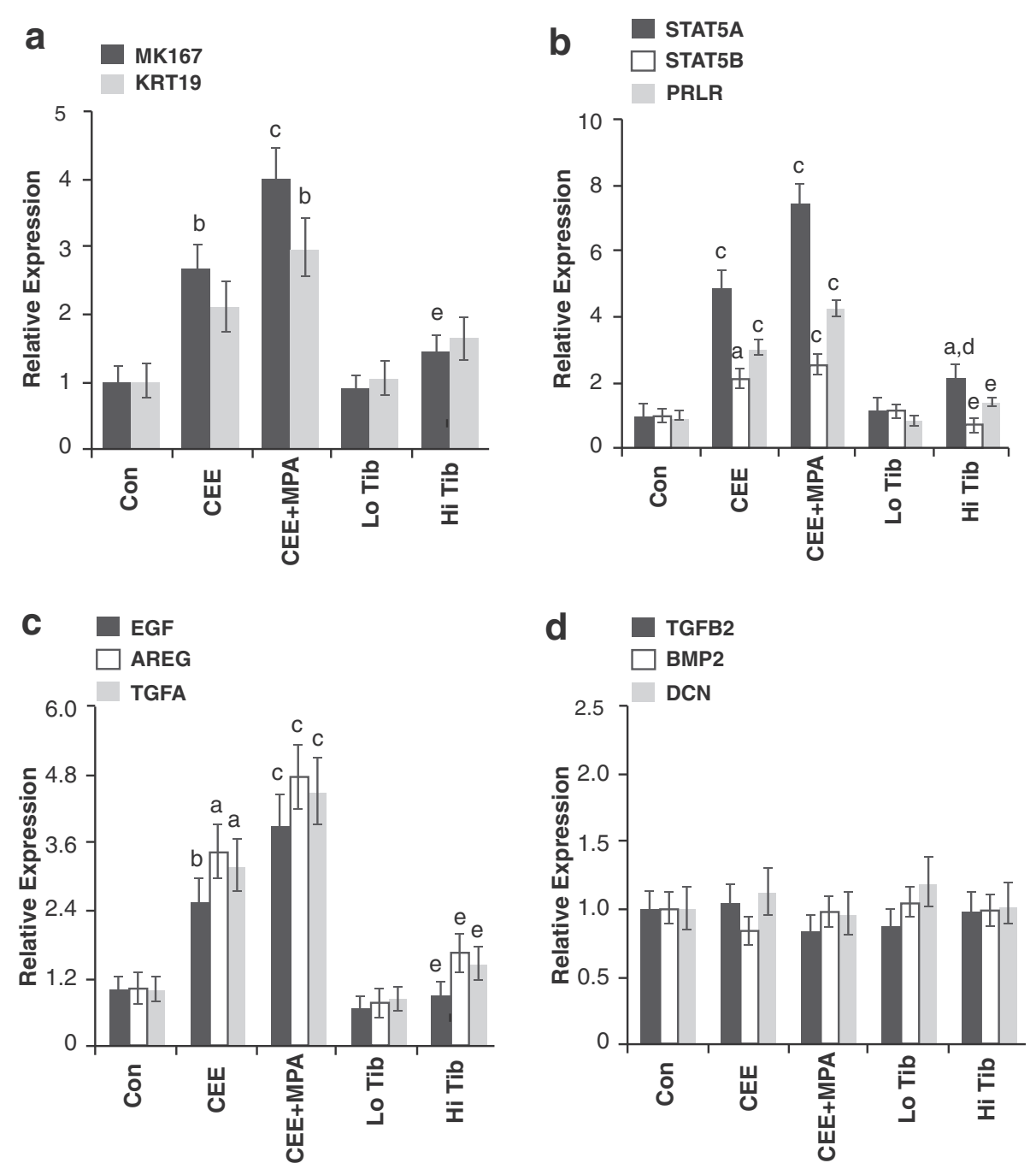

Figure 2 Hormone therapy effects on gene markers related to mammary gland proliferation. (a) markers included cell proliferation (MKI67) and epithelial density (KRT19) and genes involved in the following signaling pathways; (b) STAT5; (c) EGFR; and (d) TGF-beta. mRNA levels were determined by quantitative PCR. Vertical lines indicate 90\% confidence interval. Letters indicate significant differences compared with control $\left(P<0.05^{a}, P<0.01^{b}, P<0.001^{c}\right)$ and conjugated equine estrogens plus medroxyprogesterone acetate (CEE $\left.+\mathrm{MPA}\right),\left(P<0.01^{d}, P<0.001^{\mathrm{e}}\right)$ groups.

\section{Adding a progestin to ET inhibits ER activity}

We next examined whether patterns of ER activity were associated with treatment differences in proliferation and growth factor expression. Treatment with CEE markedly induced gene markers of ER activity, whereas the addition of MPA completely or partially antagonized this effect (depending on the marker). For example, CEE increased trefoil factor 1 (TFF1) expression by 82-fold, whereas CEE + MPA was not different from placebo (Figure 3a). For other ERinduced markers such as progesterone receptor $(P G R)$ and growth regulation by estrogen in breast cancer 1 (GREB1), the addition of MPA blocked $75 \%$ and $71 \%$ of CEE-induced expression, respectively. This pattern was also present on microarray analysis, where the primary cluster of genes differentially altered between CEE and CEE + MPA groups were related to ER signaling. The gene cluster included TFF1, PGR, GREB1, and other ER-sensitive genes such as insulin-like growth factor binding protein 1 (IGFBP1), breast carcinoma amplified sequence, and fibulin. Tibolone had a mixed pattern of effects on ER activity, inducing $P G R$ and GREB1 ( $P<0.001$ for both compared with control) but not TFF1 at the higher dose (Figure 3a). Treatment effects on ER activity were not directly associated with changes in expression of ER-alpha (ESR1), ER-beta (ESR2) (Figure 3b), or key genes related to estradiol metabolism (Figure 3c, 3d). However, ER immunolabeling was lower for ESR1 following CEE + MPA but not CEE as described previously [25]. In contrast to growth factors, markers of ER activity showed modest (PGR and GREB1) or no (TFF1) significant correlation with proliferation [see Additional file 2: Figure S1c]. 

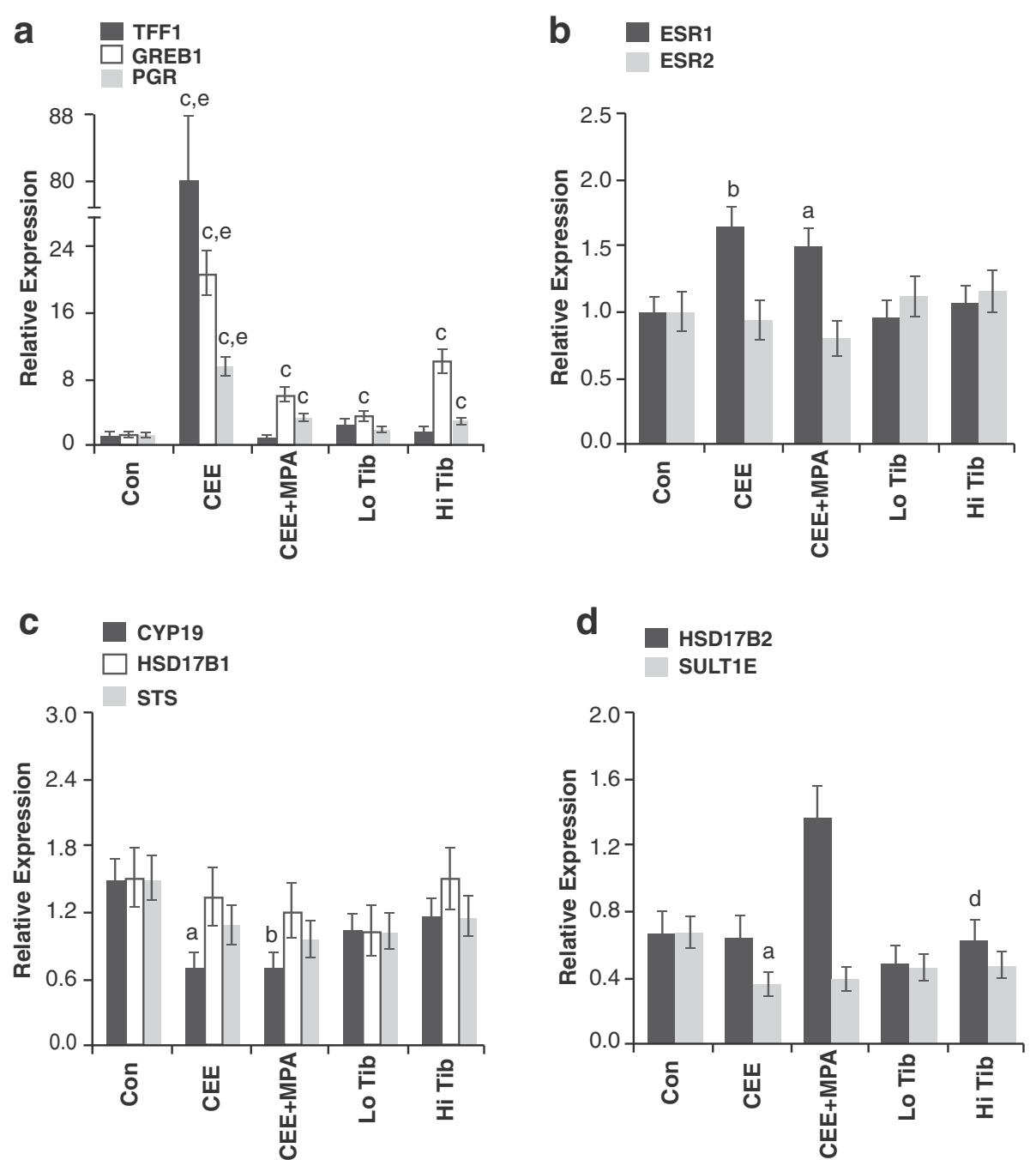

Figure 3 Hormone therapy effects on gene markers related to ER expression and activation. (a) Hormone therapy effects on gene markers related to oestrogen receptor (ER) activation; (b) ER expression; (c) estradiol synthesis and bioactivation; and (d) estradiol deactivation. mRNA expression levels were determined by quantitative PCR. Vertical lines indicate $90 \%$ confidence interval. Letters indicate significant differences compared with control $\left(P<0.05^{a}, P<0.01^{b}, P<0.001^{\circ}\right)$ and conjugated equine estrogens plus medroxyprogesterone acetate $(C E E+$ MPA) $\left(P<0.01^{d}, P<0.001^{e}\right)$ groups.

Tibolone treatment does not induce growth factor signals The main transcriptional pattern among genes altered by the Hi Tib dose related to ER signaling; no other clear patterns were noted. Of the 24 identified genes with more than three FC and $P<0.05$ compared with control, 20 genes were upregulated. Among these, there were seven known ER-sensitive genes (PGR, GREB1, stanniocalcin 2 [STC2], secretoglobin family $1 \mathrm{D}$ member 2 [SCGB1D2], kallikreins 11 [KLK11] and 12 [KLK12], and IGFBP1); two genes involved in steroid metabolism (cytochrome p450 family 2 subfamily A polypeptide 7 [CYP2A7] and 3-betahydroxysteroid dehydrogenase $\Delta-5-\Delta-4$ isomerase type II [HSD3B2]); two secretoglobins (SCGB3A1 and SCGB1D2); and three peptidases (disintegrin and metalloproteinase with thrombospondin motifs 8 [ADAMTS8], KLK11, and KLK12). Notably, isoforms of HSD3B are the primary enzymes driving production of the progestogenic delta-4 tibolone metabolite [13]. Despite a $6.5 \mathrm{FC}$ increase in HSD3B2 expression in the Hi Tib group, no markers of progestogenic activity were noted.

\section{EPT increases RANK/RANKL pathway expression}

The RANK pathway exhibits crosstalk with both STAT5 [26] and EGFR [27] signaling and contributes to progestogen-induced cell proliferation in the mouse mammary gland [28,29]. Mouse mammary expression of RANKL is increased substantially after progestin treatment [30], and increased RANK expression is observed at ductal side 
branches and alveoli during pregnancy-induced mammary morphogenesis [31]. To further explore hormonal regulation of this pathway in the primate mammary gland, we evaluated ET and EPT effects on expression of mRNAs encoding RANK, RANKL, and the endogenous inhibitor of RANKL, osteoprotegerin (OPG). No significant group differences in RANK, RANKL, or OPG expression were noted in analysis by microarray. By qPCR, treatment with CEE alone did not result in significant changes in $R A N K$, $R A N K L$, or OPG expression (Figure 4a), whereas treatment with CEE + MPA resulted in a significantly higher expression of $R A N K$ and lower expression of OPG relative to
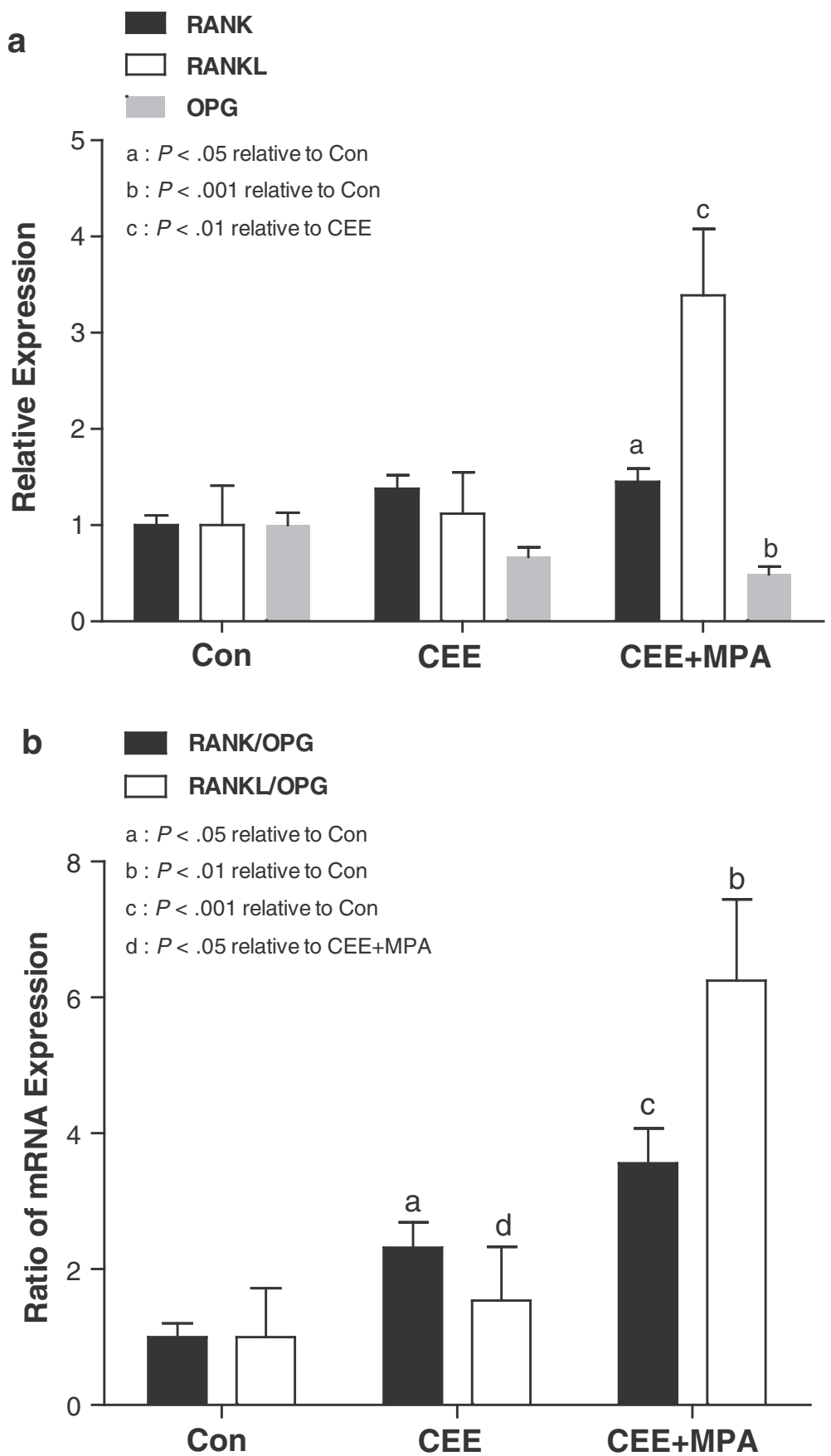

Figure 4 Hormone therapy effects on gene markers of RANK/RANKL signaling. (a) mRNA expression of RANK, RANKL, and the endogenous inhibitor of RANKL signaling $(O P G)$ and (b) ratios between these markers. mRNA levels were determined by quantitative PCR and expressed as (a) relative means or as (b) ratios of RANK/OPG or RANKL/OPG. Vertical lines indicate $90 \%$ confidence interval. Letters indicate significant differences between groups as indicated. 
control $(P<0.05$ and $P<0.001$, respectively; Figure 4a). Treatment with CEE + MPA also increased RANKL mRNA more than three-fold versus control and the differences between RANKL mRNA levels after CEE + MPA versus CEE treatment were statistically significant $(P<0.01)$. Analysis of $R A N K L$ mRNA changes was confounded by one animal in the CEE-treated cohort which had more than 50-fold higher levels of $R A N K L$ mRNA than all other animals. Treatment with CEE + MPA resulted in greater ratios of $R A N K$ and RANKL to OPG compared with control $(P<0.001$ and $P<$ 0.01 , respectively; Figure $4 \mathrm{~b}$ ) and greater ratio of $R A N K L$ to OPG compared with the CEE group $(P<0.05$; Figure $4 \mathrm{~b})$.
Although RANKL mRNA levels did not correlate with $M K I 67$ [see Additional file 3: Figure S2a], the ratios of RANKL:OPG and RANK:OPG expression showed a significant positive association with MKI67 (Figure 5), with the strongest correlations observed in the $\mathrm{CEE}+\mathrm{MPA}$ group ( $\mathrm{R}=0.59, P=0.0007$ and $\mathrm{R}=0.64, P=0.0002$, respectively). The $R A N K / O P G$ ratio expression also showed a significant positive association with STAT5A $(\mathrm{R}=0.69, P<0.0001)$ and KRT19 ( $\mathrm{R}=0.55, P<0.0001)$, whereas $R A N K L / O P G$ ratio showed significant positive, yet modest, correlations with STAT5A and KRT19 $(\mathrm{R}=0.35, P=0.0008$ and $\mathrm{R}=0.29$, $P=0.006$, respectively) [see Additional file 4: Figure S3].
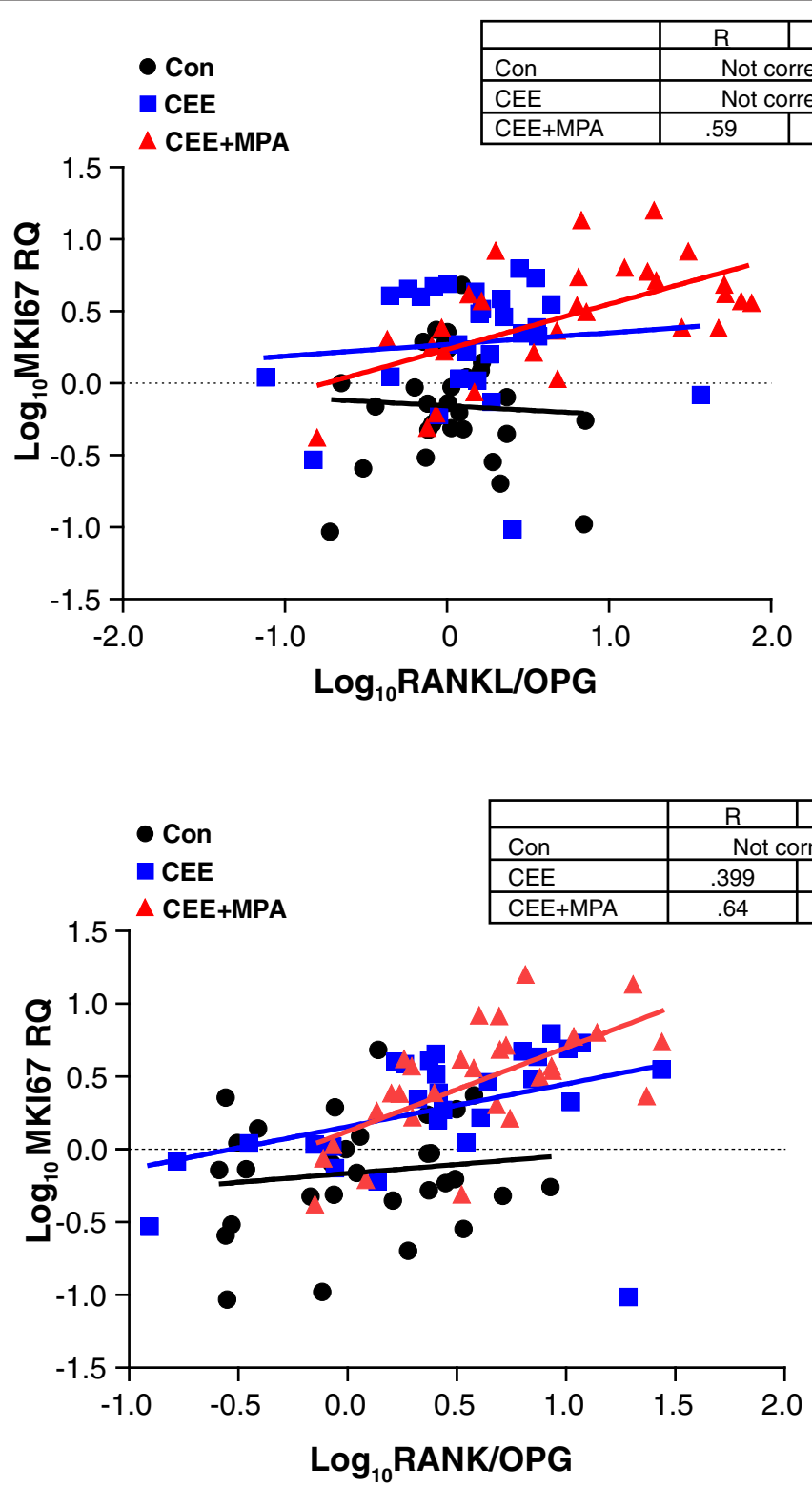

Figure 5 Regression analysis for expression of the proliferation marker MKI67 versus RANKL/OPG or RANK/OPG mRNA ratios. Correlation of MKI67 and the RANKL/OPG MRNA ratio was only observed within the conjugated equine estrogens plus medroxyprogesterone acetate (CEE + MPA) group and not in the control or CEE groups. The strongest correlation of MKI67 and RANK/OPG mRNA ratio was observed in the CEE + MPA group. 


\section{RANKL and RANK protein show distinct patterns of expression in the mammary gland}

We next utilized IHC with monoclonal antibodies against huRANKL or huRANK to verify that the observed changes in mRNA expression were translated into protein and to determine precise cellular localization for each protein. RANKL protein was not observed within the mammary epithelium of postmenopausal monkeys in the control group but was selectively increased in the CEE + MPA group (Figures 6a; 7a, b). In contrast, RANK protein in the mammary gland was prevalent across all groups ( $>50 \%$ of monkeys in each group; Figures $6 \mathrm{~b} ; 7 \mathrm{a}$ ) with a modestly lower composite score for the CEE and CEE + MPA groups compared with control $(P<0.05$ and $P<0.01$, respectively; Figure $7 \mathrm{~b}$ ). RANKL protein expression was observed exclusively within luminal epithelial cells of ducts and lobuloalveolar structures, such that RANKL-positive cells were adjacent to RANKLnegative cells (Figure 6a). Dual immunostaining of samples from CEE + MPA-treated monkeys indicated that RANKL protein was localized in PGR-expressing luminal epithelial cells of ducts and lobuloalveolar structures [see Additional file 5: Figure S4], similar to what has been described in mice [28] and humans [32]. Expression of RANK protein was not uniform within the mammary gland, showing segmental foci of positive staining predominately within ducts and lobuloalveoli (Figure 6b). Furthermore, RANK protein expression was observed in basal cells and other epithelial cells that extended from the basal compartment to the lumen. Immunostaining of both RANK and RANKL was predominately limited to mammary epithelium, with rare expression in infiltrating cells (presumed lymphocytes). Staining was cytoplasmic and membranous for both RANK and RANKL, often with a granular cytoplasmic appearance for RANKL. This cellular distribution of RANK and RANKL protein within the monkey mammary gland was similar to that observed in mice $[28,31]$ and tissue from normal human breast (Branstetter and Dougall, manuscript in preparation).

\section{RANKL and RANK protein expression is associated with mammary epithelial cell proliferation}

The intensity of RANKL protein expression determined by IHC showed a significant positive correlation with RANKL mRNA within the CEE + MPA group $(R=0.62$, $P=0.0004$ ) but not the control and CEE groups [see Additional file 6: Figure S5]. Previous analysis using Ki-67 IHC defined a mammary epithelial proliferative response specifically in the CEE + MPA group, with the majority of labeling in the lobuloalveolar compartment and minimal Ki-67 increases observed in large ducts [21]. Here, RANKL protein expression within the CEE + MPA group was significantly correlated with the degree of proliferation as determined by $\mathrm{Ki}-67 \mathrm{IHC}$ in both alveoli $(\mathrm{R}=0.48$,
$P=0.009$; Figure $8 \mathrm{a})$ and ducts $(\mathrm{R}=0.6, P=0.002$; Figure $8 \mathrm{~b}$ ); there were no significant positive correlations of RANKL protein and Ki-67 IHC within control or CEEtreated groups (Figure 8a, 8b). RANK protein and mRNA were not significantly correlated in any group [see Additional file 6: Figure S5]. Although the intensity of RANK protein was not correlated with the degree of proliferation in any group [see Additional file 7: Figure S6], dual labeling of RANK and Ki-67 was observed in a subset of proliferating breast epithelial cells from CEE + MPAtreated monkeys. Segmental foci of breast epithelium that stained positively for RANK were also frequently positive for Ki-67 whereas RANK-negative regions of the same breast tissue often had few or no Ki-67 labeled cells [see Additional file 8: Figure S7]. In addition, clear examples of individual cells positive for both RANK and Ki-67 were observed in ducts and lobuloalveolar structures [see Additional file 8: Figure S7].

\section{Discussion}

The addition of a progestin to ET is associated with increased breast tissue proliferation [33], mammographic density [4], and breast cancer risk in postmenopausal women $[4,7,8]$. Molecular mechanisms driving these effects are not clearly defined. In this study we show that adding the progestin MPA to CEE dramatically altered the mRNA profile in the normal primate mammary gland. This change was associated with greater mammary gland proliferation, decreased markers of ER activity, and increased markers of growth factor signaling. Many of the progestin-dependent changes observed here are also seen in the mouse mammary gland and have been associated with mammary carcinogenesis. These findings identify key differences among common types of menopausal HTs and highlight specific pathways relevant to hormonal promotion of mammary epithelial cell growth.

Our results show clear differences between ET and EPT effects on breast tissue and support the hypothesis that EPT increases cell proliferation beyond that of ET alone due in part to specific growth factor signals. Three primary progestin-regulated pathways were identified in this study: prolactin receptor (PRLR)/STAT5, EGFR, and RANK/RANKL. The STAT5 pathway has been shown to mediate PRLR activity and regulate mammary gland development, differentiation, and proliferation [26,34], whereas EGFR is a central growth factor pathway in mammary gland development and a subset of breast cancers [35]. Both PRLR/STAT5 and EGFR pathways are also known targets of progestogen action in the mouse mammary gland [36,37].

RANK/RANKL is the third pathway selectively modified by the combination of CEE + MPA. This pathway has important roles in lymph node development during 


\section{a RANKL}
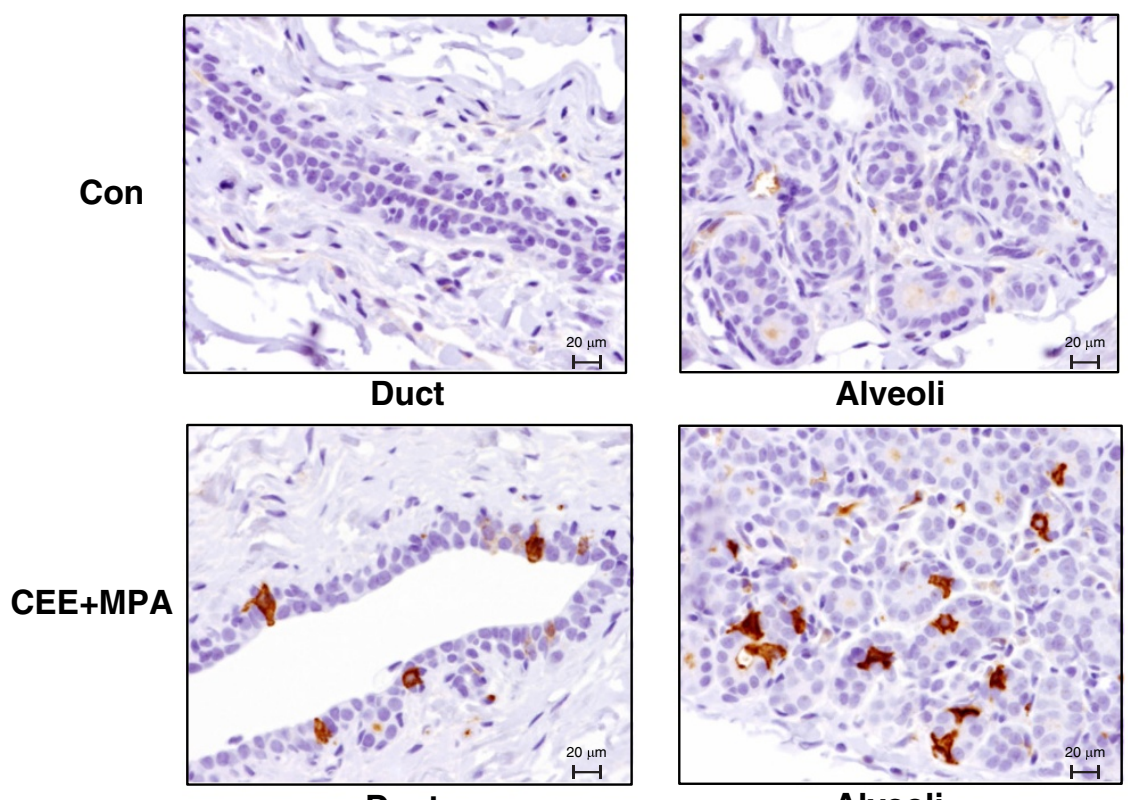

Duct

Alveoli

\section{b RANK}
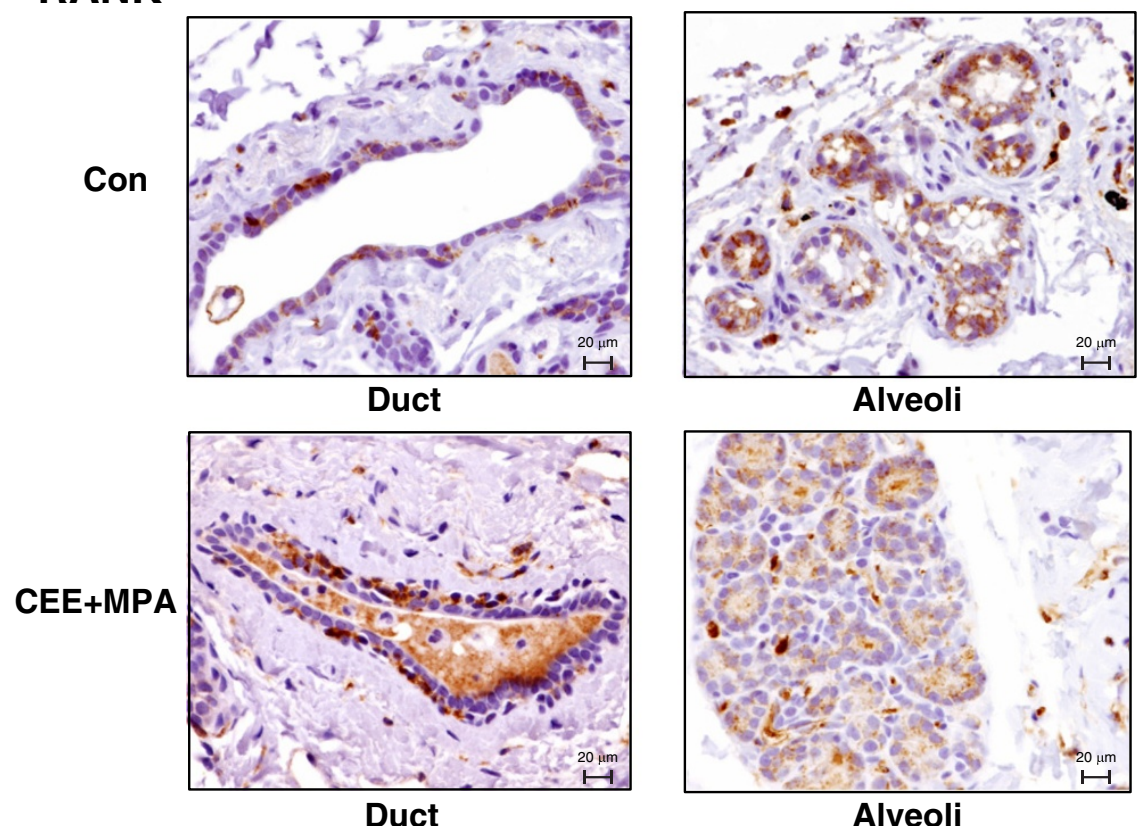

Alveoli

Figure 6 Expression and localization of RANKL and RANK protein within the mammary gland. $(\mathbf{a}, \mathbf{b})$ Representative images of RANKL and RANK immunohistochemical staining in control and conjugated equine estrogens plus medroxyprogesterone acetate (CEE + MPA) groups. There is no detectable staining for RANKL in the control group but RANKL protein is clearly evident exclusively within the luminal epithelial cells of the lobuloalveolar and ductal epithelium in the CEE + MPA group. RANKL was not detected within myoepithelial, stromal, or infiltrating immune cells. RANK expression was observed in both ductal and lobuloalveolar structures in all groups. RANK protein was predominately observed in basal cells in close proximity to the basement membrane and also in some epithelial cells, which extended from the basement matrix/basal layer to the lumen. The observed staining of intraluminal secretory material using the RANK antibodies was due to non-specific binding to proteinaceous material in serum (data not shown). 


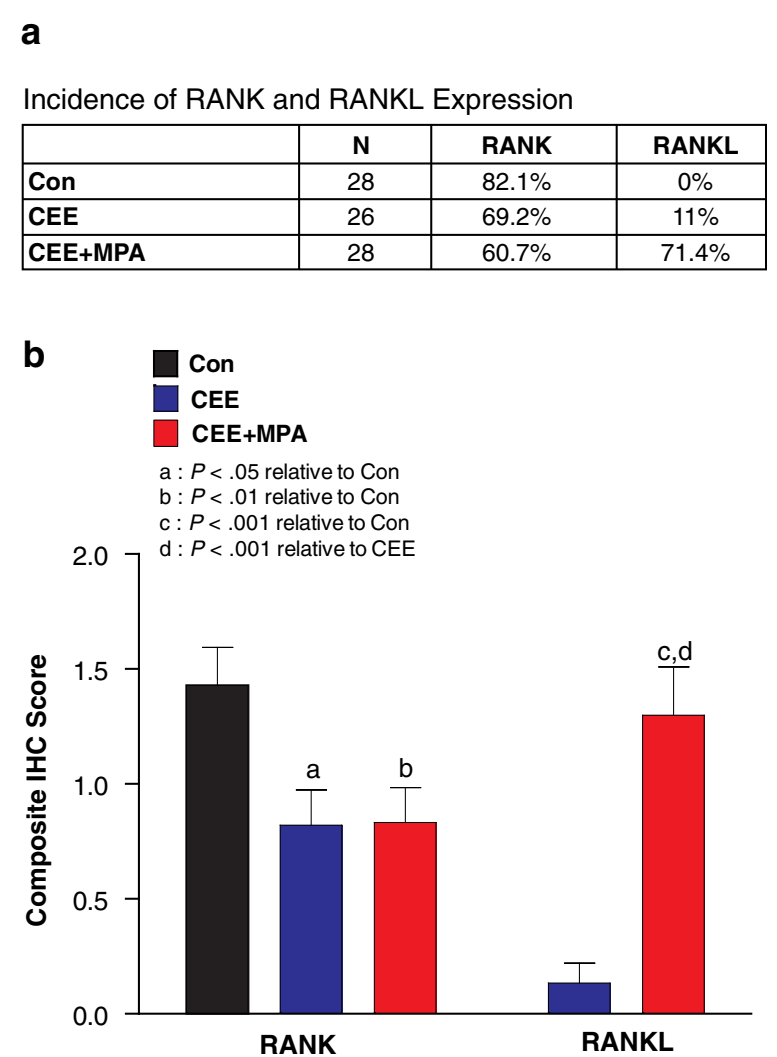

Figure 7 Hormone therapy effects on incidence of expression and intensity of IHC staining for RANK and RANKL. (a) Incidence score for RANK or RANKL immunohistochemical (IHC) positivity in each group. (b) Mean composite IHC score +/standard error of the mean in each treatment group. Letters indicate significant differences versus control $\left(P<0.05^{a}, P<0.01^{b}\right.$, $P<0.001^{c}$ ) or conjugated equine estrogens (CEE) $\left(P<0.001^{\mathrm{d}}\right.$ ) groups.

embryogenesis and is essential for the formation, function, and survival of bone-resorbing osteoclasts [38]. Modulation of the latter mechanism is the basis for the development of the fully human monoclonal antibody to RANKL, denosumab, recently approved for the prevention of skeletal-related events in patients with bone metastases from solid tumors [39]. Analysis of RANK- and RANKLknockout mice revealed defective mammary alveologenesis [40], which resembled the mammary morphogenic defect observed in PGR-knockout mice [41]. Transcription of RANKL is rapidly induced upon progesterone exposure in mice [30] and co-localized with PGR within "transmitter" ER/PGR-positive luminal mammary epithelial cells [42]. Subsequent studies have shown that RANKL is an essential paracrine mediator of progesterone function in the mouse mammary gland, leading to both mammary epithelial proliferation [43] and the transient expansion and increased regenerative potential of mammary stem cells $[44,45]$ during pregnancy and the estrous cycle. Importantly, these
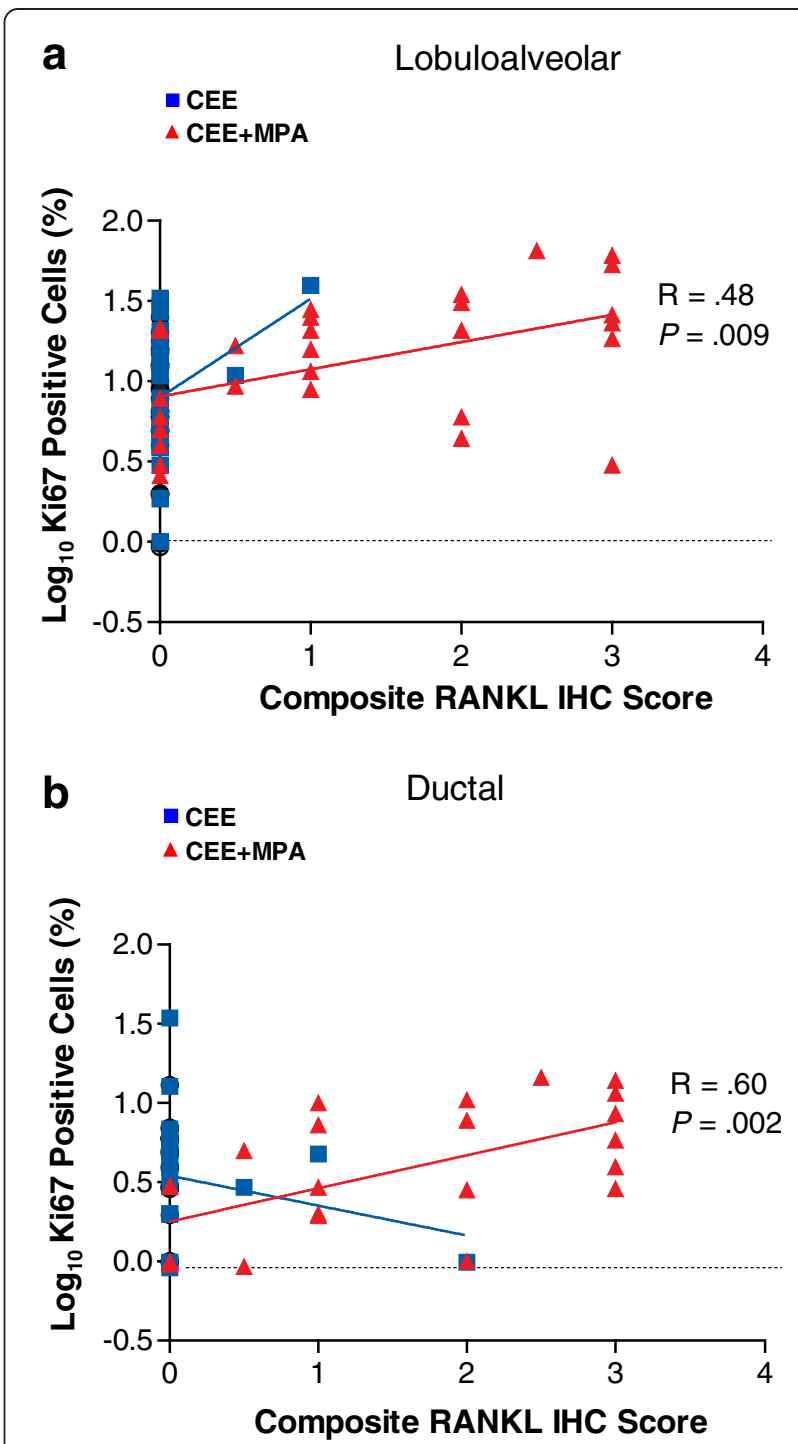

Figure 8 Correlation of RANKL protein expression with Ki-67 protein expression. Regression analysis for expression of the proliferation marker Ki-67 (immunohistochemical (IHC)) versus RANKL protein $(\mathrm{IHC})$ in (a) lobuloalveolar or (b) ductal cells. Correlation between RANKL IHC score and percent Ki-67 positive cells is observed in conjugated equine estrogens plus medroxyprogesterone acetate (CEE + MPA) treated animals $(R=0.48, P=0.009$ for lobuloalveolar epithelia, $R=0.6, P=0.002$ for ductal epithelia). The majority of animals within the control and CEE groups (100\% and 88\%, respectively) did not express RANKL by $I H C$, precluding an accurate correlation analysis between RANKL and Ki-67 in these groups.

functionalities are not limited to normal mammary morphogenesis and observations in rodent models have now shown that RANKL, via activation of RANK within mammary epithelium, mediates progesterone-dependent mammary tumor formation $[28,29]$.

Currently, it is unclear whether the RANK/RANKL pathway functions similarly in human breast tissue. In the current study, we show that key components of the 
RANKL pathway are expressed in the normal primate mammary gland and modulated by long-term EPT exposure at clinically relevant doses. Protein expression patterns of RANKL and RANK protein were highly similar to those seen in the mouse [28] and human mammary gland (data not shown) [32]. In each species, RANKL protein is focally expressed in discrete luminal epithelial cells of the ducts and lobules often separated by adjacent RANKL-negative cells. Dual immunolabeling revealed that RANKL protein expression was highly colocalized within PGR-positive luminal epithelial cells in this study, similar to what has been recently described in mice and humans $[28,32]$. In contrast, RANK protein is segmentally expressed, sporadically in alveoli and often in cells located along the basal aspect of ducts but also in epithelial cells that extend from the basal compartment to the lumen. Similar to observations in mice, RANKL protein levels within the mammary epithelium of macaques were clearly elevated upon exposure to estrogen with a progestin but not estrogen alone. In the CEE + MPA group, we also observed decreased mRNA expression levels of OPG, the negative regulator of RANKL, thereby increasing the ratio of either RANKL/OPG or RANK/OPG. Increased RANKL protein expression was positively associated with increased ductal and alveolar proliferation driven by EPT. RANK protein was colocalized with Ki-67 in a subset of cells, suggesting that RANKexpressing breast cells directly respond to the RANKL signal and comprise at least part of the proliferative component after progestin exposure. Altogether, multiple mechanisms of hormone-dependent control contributing to the net increase in RANKL signal were identified and shown to be positively associated with increased epithelial proliferation (MKI67) and density (KRT19), suggesting that this pathway may be utilized across mammalian species for progestogen-dependent breast proliferation.

In premenopausal women, ovarian-produced progesterone may also contribute to the established relation between breast cancer risk and number of menstrual cycles or reproductive history [46], potentially via increased breast proliferation [47] and the non-proliferative expansion of normal or transformed mammary stem cells $[44,45,48]$. Using a candidate gene approach, a recent study identified RANKL, c-Kit, and gene signatures representing MaSC or luminal progenitors as each being associated with younger age at breast cancer diagnosis [49]. Although the relative contribution of RANKL mRNA from normal breast versus tumor tissue was not specified in this analysis of patients with breast cancer, the authors concluded that the strong correlation of these gene sets (including RANKL expression) was independent of breast cancer subtype and instead represented unique biological pathways common to breast cancer in young women and perhaps related to the poor prognosis in these patients. Given the present evidence, the increased mammary mitogenesis observed during the progesterone-dominant luteal phase of the human menstrual cycle [47] could involve an operative role of RANKL. Recent gene expression analysis of fine-needle aspirates of human breast tissue demonstrating significant upregulation of RANKL mRNA during the luteal phase [50] is consistent with this notion. In fact, a recent publication [32] has demonstrated that RANKL levels in the human breast are correlated with serum progesterone levels. Furthermore, RANKL was not only sufficient to induce human breast cell proliferation but was also required for progesterone-induced breast cell proliferation. These data, with observations presented in this primate study, suggest that the increased RANKL signal in human breast tissue is a consequence of progestogen exposure in postmenopausal women or luteal phase ovarian progesterone in premenopausal women. Moreover, this increased RANKL may be correlated with the proliferative status and overall density of the mammary epithelium and contribute to hormone-dependent breast tumor formation.

The three signaling pathways identified here as being selectively increased by EPT all exhibit signaling cross-talk that may be functionally important in breast cancer. Prior studies have shown that the induction of RANKL by MPA requires expression of PRLR and that prolactin signaling is necessary for nuclear translocation of STAT5A after EPT $[29,51]$. These findings also indicate that the interferongamma responsive elements identified within the RANKL promoter are essential for activation of the JAK2/STAT5A response [51] and potentially important for progestogendependent increases. Other studies have shown that nuclear phosphorylated STAT5A is co-localized with PGR and RANKL in cells after EPT [26], further suggesting that progestogen-dependent increases in RANKL transcription may be governed at the RANKL promoter, at least in part, by a complex of PGR and STAT5A, similar to that observed with the $\beta$-casein promoter [52]. Finally, EGFR ligands have been shown to strongly decrease OPG expression in an EGFR-dependent manner [27] and activate STAT5A in mammary tissue [53]. Collectively, these data support a model in which progestogen activity in breast tissue may increase RANKL protein expression either directly, or indirectly, via PRLR/STAT5 signaling, whereas OPG protein expression may be decreased via EGFR signaling. Future studies are warranted to determine if multifactorial convergences of the PRLR/STAT5, EGFR, and RANK/RANKL pathways may contribute to breast cancer risk.

Unlike EPT, tibolone did not show a clear induction of mRNA markers in breast tissue related to growth factor signaling. This finding is consistent with the lack of increased mammary epithelial Ki-67 labeling reported previously [21] and the lack of increased breast cancer risk among older postmenopausal women receiving tibolone in the LIFT clinical trial [12]. In contrast, tibolone treatment 
in the LIBERATE clinical trial was associated with a $40 \%$ increased risk of recurrence among breast cancer patients with ER-positive tumors and vasomotor symptoms [15]. Sub-group analysis among women receiving adjuvant endocrine therapy indicated that tibolone interference was greater for aromatase inhibitors (which decrease systemic and local estrogen) than for tamoxifen (which blocks ERs). The authors of the study suggest that these findings point to potential ER agonist effects of tibolone on occult, estrogen-sensitive metastases [15]. Results from the current study provide limited support for this idea, showing modest estrogenic effects of tibolone on some gene markers of ER activity but no clear progestogenic effects or activity related to specific growth factor pathways.

\section{Conclusions}

Minimizing breast cancer risk by mitigating potential adverse effects of hormonal agents is a central challenge in women's health. Results of this study expand the current understanding of transcriptional patterns and signaling pathways underlying HT effects in mammalian breast tissue. Findings presented here identify PRLR/STAT5, EGFR, and RANK/RANKL as molecular pathways that may be relevant to increased breast tissue proliferation, mammographic density, and breast cancer risk in postmenopausal women taking EPT. These pathways are potential targets for assessing and preventing progestogen-associated risk, and this information should help inform clinical strategies to better prevent hormone-associated breast cancer and recurrence.

\section{Additional files}

Additional file 1: Table S1. Primer/probe sets for target genes

evaluated by quantitative PCR.

Additional file 2: Figure S1. Regression analysis for expression of the proliferation marker MKI67 and markers of STAT5, epidermal growth factor receptor (EGFR), and estrogen receptor (ER) signaling pathways. (a) MKI67 mRNA versus STAT5 markers; (b) MKI67 mRNA versus EGFR markers; and (c) MKI67 mRNA versus ER markers. Across all groups, the strongest positive correlations were observed between MKI67 versus STAT5A, PRLR, amphiregulin (AREG), and transforming growth factor-alpha (TGFA) $(P<0.0001$ for all).

Additional file 3: Figure S2. Regression analysis for MKI67 versus RANKL and RANK. (a) RANKL mRNA versus MKI67. (b) RANK mRNA versus MKI67. Significant positive correlations were observed between RANK versus MKI67 $(R=0.48, P<0.0001)$.

Additional file 4: Figure S3. Regression analysis for STAT5A or a marker for breast density (KRT19) versus RANKL/OPG or RANK/OPG mRNA ratios. (a) RANKL/OPG mRNA ratio versus STAT5A. (b) RANK/OPG mRNA ratio versus STAT5A. (c) RANKL/OPG mRNA ratio versus KRT19. (d) RANK/OPG mRNA ratio versus KRT19. Significant positive correlations were observed between RANK OPG versus STAT5A $(R=0.69, P<0.0001)$ and RANK/OPG versus KRT19 $(R=0.55$, $P<0.0001)$. RANKL/OPG versus STAT5A or KRT19 show modest positive correlations ( $R=0.35, P=0.0008$ and $R=0.29, P=0.006$, respectively).

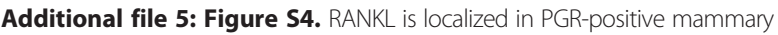
luminal epithelial cells. Representative examples of immunohistochemical colabeling of RANKL and PGR in breast tissue from conjugated equine estrogens plus medroxyprogesterone acetate (CEE + MPA) treated monkeys.
RANKL is red and PGR is brown. (a) RANKL and PGR labeling in breast duct (40X); (b) RANKL and PGR labeling in lobuloalveolar structure (60X). RANKL and PGR protein is clearly evident exclusively within the luminal epithelial cells of the lobuloalveolar and ductal epithelium. Cytoplasmic and membrane RANKL expression is localized in PGR expressing cells.

Additional file 6: Figure S5. Correlation of either RANKL or RANK protein expression with corresponding mRNA expression. (a) RANKL protein immunohistochemical $(I \mathrm{HC})$ score versus RANKL mRNA. A significant positive correlation was observed in the conjugated equine estrogens plus medroxyprogesterone acetate (CEE + MPA) group $(R=0.62, P=0.0004)$ only. The majority of animals within the control and CEE groups (100\% and $88 \%$, respectively) did not express RANKL by IHC, precluding correlation analysis between protein and mRNA expression in these groups. (b) RANK protein IHC score versus RANK mRNA. There were no significant correlations in any group.

Additional file 7: Figure S6. Correlation of RANK protein expression with Ki-67 protein expression. RANK composite immunohistochemical ( $(\mathrm{HC})$ score versus $\log _{10}$ Ki-67 positive cells (\%) in (a) lobuloalveolar or (b) ductal cells. No correlation between RANK IHC score and Ki-67 positive cells (\%) was observed.

Additional file 8: Figure S7. Dual labeling of RANK protein expression and $\mathrm{Ki}-67$ in breast epithelium from conjugated equine estrogens plus medroxyprogesterone acetate (CEE + MPA) treated monkeys. (a to d) Representative examples of immunohistochemical (IHC) co-labeling of RANK and $\mathrm{Ki}-67$ in breast tissue from CEE + MPA-treated monkeys. RANK is red and $\mathrm{Ki}-67$ is brown. Nuclear staining of Ki-67 was observed in a subset of cells with cytoplasmic and membrane expression of RANK. Low magnification views ( $a, 10 X ; b, 40 X)$ of breast tissue demonstrate segmental foci of breast epithelium stained positively for RANK that were also frequently positive for Ki-67 (as circumscribed by dashed lines). Conversely, RANK-negative regions of the same breast tissue often had few or no Ki-67 labeled cells. (c and d) Higher magnification views (60X) show clear examples of individual cells positive for both RANK and Ki-67 in (c) ducts and (d) lobuloalveolar structures. Individual ductal cells positive for both Ki-67 and RANK are indicated by arrows. In the example of staining in lobuloalveolar tissue, the majority of this particular segment stains positively for RANK (similar to that shown in Figure $6 \mathrm{~b}$ and Additional file 8: Figure $57 \mathrm{a}, \mathrm{b}$ ) with Ki-67 staining in a subset of these RANK-positive cells.

\section{Abbreviations}

ACTB: Beta-actin; ANOVA: Analysis of variance; AREG: Amphiregulin; CEE: Conjugated equine estrogens; EGFR: Epidermal growth factor receptor; EPT: Estrogen + progestin therapy; ER: Estrogen receptor; ESR1: Estrogen receptor-alpha; ESR2: ER-beta; ET: Estrogen-alone therapy; FC: Fold change; GAPDH: Glyceraldehyde-3-phosphate dehydrogenase; GREB1: Growth regulation by estrogen in breast cancer 1; HSD17B1: 17-beta hydroxysteroid dehydrogenase type 1; HSD17B2: 17-beta hydroxysteroid dehydrogenase type 2; HSD3B: 3-beta-hydroxysteroid dehydrogenase/delta-5-delta-4 isomerase; HT: Hormone therapy; IGFBP1: Insulin-like growth factor binding protein 1; IHC: Immunohistochemical; KRT19: Keratin 19; MKI67: Antigen identified by monoclonal antibody Ki-67; MPA: Medroxyprogesterone acetate; OPG: Osteoprotegerin; PCA: Principal components analysis; PGR: Progesterone receptor; PRLR: Prolactin receptor; qPCR: Quantitative real-time polymerase chain reaction; RANK: Receptor activator of nuclear factor kappa B; RANKL: Receptor activator of nuclear factor kappa B ligand; SA-HRP: Streptavidin-horseradish peroxidase; STAT5: Signal transducer and activator of transcription 5; TFF1: Trefoil factor 1; TGF: Transforming growth factor; Tib: Tibolone; WHI: Women's Health Initiative.

\section{Competing interests}

$\mathrm{CW}$ has received research funding from Amgen Inc and Pfizer; $\mathrm{DB}, \mathrm{AJ}, \mathrm{KR}, \mathrm{LH}$, and WD are employees and have received stock from Amgen Inc; JC has consulted and received research funding from Amgen Inc; TR and HB have no disclosures.

\section{Authors' contributions}

Conception and design: CW, WD, and DB. Development of methodology: $C W, W D, D B, H B, L H, K R$, TR. Acquisition of data: CW, WD, LH, DB, and JC. Analysis and interpretation of data: CW, AJ, WD, DB, and JC. Writing, review, and/or revision of the manuscript: CW, AJ, WD, DB, TR, and JC. All authors read and approved the manuscript. 


\section{Acknowledgments}

The authors would like to thank Lisa O'Donnell and Jean Gardin for their technical contributions, Tony Polverino for critical reading of the manuscript, and Albert Y. Rhee (Amgen Inc.) for editing assistance. This work was supported by research grants from the National Institutes of Health (K01 RR 021322-05) and Amgen Inc. Support for the original animal study was provided by NV Organon.

\section{Author details}

'Department of Pathology, Section on Comparative Medicine, Wake Forest University School of Medicine, Winston-Salem, NC 27157, USA. ${ }^{2}$ Department of Pathology, Amgen Inc, Seattle, WA 98119, USA. ${ }^{3}$ Therapeutic Innovation Unit (TIU), Amgen Inc, Seattle, WA 98119, USA.

Received: 29 January 2013 Accepted: 22 July 2013

Published: 12 August 2013

\section{References}

1. Hersh AL, Stefanick ML, Stafford RS: National use of postmenopausal hormone therapy: annual trends and response to recent evidence. JAMA 2004, 291:47-53.

2. Pike MC, Peters RK, Cozen W, Probst-Hensch NM, Felix JC, Wan PC, Mack TM: Estrogen-progestin replacement therapy and endometrial cancer. J Natl Cancer Inst 1997, 89:1110-1116.

3. Rossouw JE, Anderson GL, Prentice RL, LaCroix AZ, Kooperberg C, Stefanick ML, Jackson RD, Beresford SA, Howard BV, Johnson KC, Kotchen JM, Ockene J, Writing Group for the Women's Health Initiative Investigators: Risks and benefits of estrogen plus progestin in healthy postmenopausal women: principal results From the Women's Health Initiative randomized controlled trial. JAMA 2002, 288:321-333.

4. Chlebowski RT, Hendrix SL, Langer RD, Stefanick ML, Gass M, Lane D, Rodabough RJ, Gilligan MA, Cyr MG, Thomson CA, Khandekar J, Petrovitch H, McTiernan A, WHI Investigators: Influence of estrogen plus progestin on breast cancer and mammography in healthy postmenopausal women: the Women's Health Initiative Randomized Trial. JAMA 2003, 289:3243-3253.

5. Chlebowski RT, Anderson GL, Gass M, Lane DS, Aragaki AK, Kuller LH, Manson JE, Stefanick ML, Ockene J, Sarto GE, Johnson KC, WactawskiWende J, Ravdin PM, Schenken R, Hendrix SL, Rajkovic A, Rohan TE, Yasmeen S, Prentice RL, WHI Investigators: Estrogen plus progestin and breast cancer incidence and mortality in postmenopausal women. JAMA 2010, 304:1684-1692.

6. Chlebowski RT, Kuller LH, Prentice RL, Stefanick ML, Manson JE, Gass M, Aragaki AK, Ockene JK, Lane DS, Sarto GE, Rajkovic A, Schenken R, Hendrix SL, Ravdin PM, Rohan TE, Yasmeen S, Anderson G, WHI Investigators: Breast cancer after use of estrogen plus progestin in postmenopausal women. N Engl J Med 2009, 360:573-587.

7. Schairer C, Lubin J, Troisi R, Sturgeon S, Brinton L, Hoover R: Estrogen-progestin replacement and risk of breast cancer. JAMA 2000, 284:691-694.

8. Ross RK, Paganini-Hill A, Wan PC, Pike MC: Effect of hormone replacement therapy on breast cancer risk: estrogen versus estrogen plus progestin. J Natl Cancer Inst 2000, 92:328-332.

9. Stefanick ML, Anderson GL, Margolis KL, Hendrix SL, Rodabough RJ, Paskett ED, Lane DS, Hubbell FA, Assaf AR, Sarto GE, Schenken RS, Yasmeen S, Lessin L, Chlebowski RT, WHI Investigators: Effects of conjugated equine estrogens on breast cancer and mammography screening in postmenopausal women with hysterectomy. JAMA 2006, 295:1647-1657.

10. LaCroix AZ, Chlebowski RT, Manson JE, Aragaki AK, Johnson KC, Martin L, Margolis KL, Stefanick ML, Brzyski R, Curb JD, Howard BV, Lewis CE, Wactawski-Wende J, WHI Investigators: Health outcomes after stopping conjugated equine estrogens among postmenopausal women with prior hysterectomy: a randomized controlled trial. JAMA 2011, 305:1305-1314.

11. Swanson SG, Drosman S, Helmond FA, Stathopoulos VM: Tibolone for the treatment of moderate to severe vasomotor symptoms and genital atrophy in postmenopausal women: a multicenter, randomized, double-blind, placebo-controlled study. Menopause 2006, 13:917-925.

12. Cummings SR, Ettinger B, Delmas PD, Kenemans P, Stathopoulos V, Verweij P, Mol-Arts M, Kloosterboer L, Mosca L, Christiansen C, Bilezikian J, Kerzberg EM, Johnson S, Zanchetta J, Grobbee DE, Seifert W, Eastell R, LIFT Trial Investigators: The effects of tibolone in older postmenopausal women. N Engl J Med 2008, 359:697-708.
13. Tang B, Markiewicz L, Kloosterboer HJ, Gurpide E: Human endometrial 3 beta-hydroxysteroid dehydrogenase/isomerase can locally reduce intrinsic estrogenic/progestagenic activity ratios of a steroidal drug (Org OD 14). J Steroid Biochem Mol Biol 1993, 45:345-351.

14. Genazzani AR, Benedek-Jaszmann LJ, Hart DM, Andolsek L, Kicovic PM, Tax L: Org OD 14 and the endometrium. Maturitas 1991, 13:243-251.

15. Kenemans P, Bundred NJ, Foidart JM, Kubista E, von Schoultz B, Sismondi P, Vassilopoulou-Sellin R, Yip CH, Egberts J, Mol-Arts M, Mulder R, van Os S, Beckmann MW, LIBERATE Study Group: Safety and efficacy of tibolone in breast-cancer patients with vasomotor symptoms: a double-blind, randomised, non-inferiority trial. Lancet Oncol 2009, 10:135-146.

16. Ismail PM, Amato P, Soyal SM, DeMayo FJ, Conneely OM, O'Malley BW, Lydon JP: Progesterone involvement in breast development and tumorigenesis-as revealed by progesterone receptor "knockout" and "knockin" mouse models. Steroids 2003, 68:779-787.

17. Pavlicek A, Noskov VN, Kouprina N, Barrett JC, Jurka J, Larionov V: Evolution of the tumor suppressor BRCA1 locus in primates: implications for cancer predisposition. Hum Mol Genet 2004, 13:2737-2751

18. Cline JM, Wood CE: The mammary glands of macaques. Toxicol Pathol 2008, 36:134s-141s.

19. Wood CE, Usborne AL, Starost MF, Tarara RP, Hill LR, Wilkinson LM, Geisinger KR, Feiste EA, Cline JM: Hyperplastic and neoplastic lesions of the mammary gland in macaques. Vet Pathol 2006, 43:471-483.

20. Cline JM, Soderqvist G, von Schoultz E, Skoog L, von Schoultz B: Effects of hormone replacement therapy on the mammary gland of surgically postmenopausal cynomolgus macaques. Am J Obstet Gynecol 1996, 174:93-100

21. Cline JM, Register TC, Clarkson TB: Effects of tibolone and hormone replacement therapy on the breast of cynomolgus monkeys. Menopause 2002, 9:422-429.

22. Clarkson TB, Anthony MS, Wagner JD: A comparison of tibolone and conjugated equine estrogens effects on coronary artery atherosclerosis and bone density of postmenopausal monkeys. J Clin Endocrinol Metab 2001, 86:5396-5404.

23. Reiner A, Yekutieli D, Benjamini Y: Identifying differentially expressed genes using false discovery rate controlling procedures. Bioinformatics 2003, 19:368-375.

24. Wood CE, Kaplan JR, Fontenot MB, Williams JK, Cline JM: Endometrial profile of tamoxifen and low-dose estradiol combination therapy. Clin Cancer Res 2010, 16:946-956.

25. Ma L, Hofling M, Masironi B, von Schoultz B, Cline JM, Sahlin L: Effects of tibolone and conventional HRT on the expression of estrogen and progesterone receptors in the breast. Maturitas 2008, 61:345-349.

26. Santos SJ, Haslam SZ, Conrad SE: Signal transducer and activator of transcription 5a mediates mammary ductal branching and proliferation in the nulliparous mouse. Endocrinology 2010, 151:2876-2885.

27. Zhu J, Jia X, Xiao G, Kang Y, Partridge NC, Qin L: EGF-like ligands stimulate osteoclastogenesis by regulating expression of osteoclast regulatory factors by osteoblasts: implications for osteolytic bone metastases. J Biol Chem 2007, 282:26656-26664.

28. Gonzalez-Suarez E, Jacob AP, Jones J, Miller R, Roudier-Meyer MP, Erwert R, Pinkas J, Branstetter D, Dougall WC: RANK ligand mediates progestininduced mammary epithelial proliferation and carcinogenesis. Nature 2010, 468:103-107.

29. Schramek D, Leibbrandt A, Sigl V, Kenner L, Pospisilik JA, Lee HJ, Hanada R, Joshi PA, Aliprantis A, Glimcher L, Pasparakis M, Khokha R, Ormandy CJ, Widschwendter M, Schett G, Penninger JM: Osteoclast differentiation factor RANKL controls development of progestin-driven mammary cancer. Nature 2010, 468:98-102.

30. Fernandez-Valdivia R, Mukherjee A, Creighton CJ, Buser AC, DeMayo FJ, Edwards DP, Lydon JP: Transcriptional response of the murine mammary gland to acute progesterone exposure. Endocrinology 2008, 149:6236-6250.

31. Gonzalez-Suarez E, Branstetter D, Armstrong A, Dinh H, Blumberg H, Dougall WC: RANK overexpression in transgenic mice with mouse mammary tumor virus promoter-controlled RANK increases proliferation and impairs alveolar differentiation in the mammary epithelia and disrupts lumen formation in cultured epithelial acini. Mol Cell Biol 2007, 27:1442-1454. 
32. Tanos T, Sflomos G, Echeverria PC, Ayyanan A, Gutierrez M, Delaloye JF, Raffoul W, Fiche M, Dougall W, Schneider P, Yalcin-Ozuysal O, Brisken C: Progesterone/RANKL is a major regulatory axis in the human breast. $\mathrm{SCl}$ Transl Med 2013, 5:182ra55.

33. Hofseth LJ, Raafat AM, Osuch JR, Pathak DR, Slomski CA, Haslam SZ: Hormone replacement therapy with estrogen or estrogen plus medroxyprogesterone acetate is associated with increased epithelial proliferation in the normal postmenopausal breast. J Clin Endocrinol Metab 1999, 84:4559-4565.

34. Miyoshi K, Shillingford JM, Smith GH, Grimm SL, Wagner KU, Oka T, Rosen $J M$, Robinson GW, Hennighausen L: Signal transducer and activator of transcription (Stat) 5 controls the proliferation and differentiation of mammary alveolar epithelium. J Cell Biol 2001, 155:531-542.

35. Sternlicht MD: Key stages in mammary gland development: the cues that regulate ductal branching morphogenesis. Breast Cancer Res 2006, 8:201.

36. Santos SJ, Haslam SZ, Conrad SE: Estrogen and progesterone are critical regulators of Stat5a expression in the mouse mammary gland. Endocrinology 2008, 149:329-338.

37. Kariagina A, Xie J, Leipprandt JR, Haslam SZ: Amphiregulin mediates estrogen, progesterone, and EGFR signaling in the normal rat mammary gland and in hormone-dependent rat mammary cancers. Horm Cancer 2010, 1:229-244

38. Nakashima T, Takayanagi $\mathrm{H}$ : Osteoimmunology: crosstalk between the immune and bone systems. J Clin Immunol 2009, 29:555-567.

39. Lipton A, Fizazi K, Stopeck AT, Henry DH, Brown JE, Yardley DA, Richardson GE, Siena S, Maroto P, Clemens M, Bilynskyy B, Charu V, Beuzeboc P, Rader M, Viniegra M, Saad F, Ke C, Braun A, Jun S: Superiority of denosumab to zoledronic acid for prevention of skeletal-related events: A combined analysis of 3 pivotal, randomised, phase 3 trials. Eur J Cancer 2012, 48:3082-3096.

40. Fata JE, Kong YY, Li J, Sasaki T, Irie-Sasaki J, Moorehead RA, Elliott R, Scully S, Voura EB, Lacey DL, Boyle WJ, Khokha R, Penninger JM: The osteoclast differentiation factor osteoprotegerin-ligand is essential for mammary gland development. Cell 2000, 103:41-50.

41. Lydon JP, DeMayo FJ, Funk CR, Mani SK, Hughes AR, Montgomery CA Jr, Shyamala G, Conneely OM, O'Malley BW: Mice lacking progesterone receptor exhibit pleiotropic reproductive abnormalities. Genes Dev 1995, 9:2266-2278.

42. Aupperlee MD, Drolet AA, Durairaj S, Wang W, Schwartz RC, Haslam SZ: Strain-specific differences in the mechanisms of progesterone regulation of murine mammary gland development. Endocrinology 2009, 150:1485-1494.

43. Beleut M, Rajaram RD, Caikovski M, Ayyanan A, Germano D, Choi Y, Schneider $\mathrm{P}$, Brisken C: Two distinct mechanisms underlie progesteroneinduced proliferation in the mammary gland. Proc Natl Acad Sci USA 2010, 107:2989-2994.

44. Asselin-Labat ML, Vaillant F, Sheridan JM, Pal B, Wu D, Simpson ER, Yasuda H, Smyth GK, Martin TJ, Lindeman GJ, Visvader JE: Control of mammary stem cell function by steroid hormone signalling. Nature 2010, 465:798-802.

45. Joshi PA, Jackson HW, Beristain AG, Di Grappa MA, Mote PA, Clarke CL Stingl J, Waterhouse PD, Khokha R: Progesterone induces adult mammary stem cell expansion. Nature 2010, 465:803-807.

46. Russo $H_{\text {, Russo }}$ : Role of hormones in mammary cancer initiation and progression. J Mammary Gland Biol Neoplasia 1998, 3:49-61.

47. Going JJ, Anderson TJ, Battersby S, Maclntyre CC: Proliferative and secretory activity in human breast during natural and artificial menstrual cycles. Am J Pathol 1988, 130:193-204.

48. Horwitz KB, Sartorius CA: Progestins in hormone replacement therapies reactivate cancer stem cells in women with preexisting breast cancers: a hypothesis. J Clin Endocrinol Metab 2008, 93:3295-3298.

49. Azim HA Jr, Michiels S, Bedard PL, Singhal SK, Criscitiello C, Ignatiadis M, Haibe-Kains B, Piccart MJ, Sotiriou C, Loi S: Elucidating prognosis and biology of breast cancer arising in young women using gene expression profiling. Clin Cancer Res 2012, 18:1341-1351.

50. Wang J, Lee $O$, Heinz R, Ivancic D, Shcholtens D, Chatterton RT, Khan SA: Identification of hormone-responsive genes as biomarkers for menstrual cycle phases and menopausal status [abstract]. Cancer 2011, 71:

51. Srivastava S, Matsuda M, Hou Z, Bailey JP, Kitazawa R, Herbst MP, Horseman ND: Receptor activator of NF-kappaB ligand induction via Jak2 and Stat5a in mammary epithelial cells. J Biol Chem 2003, 278:46171-46178.
52. Buser AC, Gass-Handel EK, Wyszomierski SL, Doppler W, Leonhardt SA, Schaack J, Rosen JM, Watkin H, Anderson SM, Edwards DP: Progesterone receptor repression of prolactin/signal transducer and activator of transcription 5-mediated transcription of the beta-casein gene in mammary epithelial cells. Mol Endocrinol 2007, 21:106-125.

53. Gallego Ml, Binart N, Robinson GW, Okagaki R, Coschigano KT, Perry J, Kopchick JJ, Oka T, Kelly PA, Hennighausen L: Prolactin, growth hormone, and epidermal growth factor activate Stat5 in different compartments of mammary tissue and exert different and overlapping developmental effects. Dev Biol 2001, 229:163-175.

doi:10.1186/bcr3456

Cite this article as: Wood et al:: Progestin effects on cell proliferation pathways in the postmenopausal mammary gland. Breast Cancer Research 2013 15:R62.

\section{Submit your next manuscript to BioMed Central and take full advantage of:}

- Convenient online submission

- Thorough peer review

- No space constraints or color figure charges

- Immediate publication on acceptance

- Inclusion in PubMed, CAS, Scopus and Google Scholar

- Research which is freely available for redistribution 